\title{
Identification of Coffee Berry Borer from Similar Bark Beetles in Southeast Asia and Oceania ${ }^{1}$
}

\author{
Andrew Johnson, Gabriel LeMay, and Jiri Hulcr²
}

\section{Introduction}

The coffee berry borer (CBB), Hypothenemus hampei, is a serious pest of coffee worldwide. It is present in every coffee-growing region, and accurate identification of $\mathrm{CBB}$ is an essential part of preventing it from harming the coffee industry. Many similar and mostly harmless bark beetles already present in tropical and subtropical areas will fly into CBB traps.

CBB belongs to a genus of bark beetles called Hypothenemus that is notoriously difficult to identify. The majority of species in this genus feed on dead plant material and are not significant pests, though there is another economically significant species, the tropical nut borer (TNB), Hypothenemus obscurus. There are also other bark beetles that may be confused with the coffee berry borer.

This guide aims to assist in the identification of $\mathrm{CBB}$ as well as similar bark beetles likely to be encountered in Southeast Asia and Oceania and potentially confused with the coffee berry borer. While it will assist in the identification of similar genera, it will not support identification to species. Useful to taxonomic specialists looking for concise distinguishing characteristics, as well as stakeholders wishing to be aware of pest descriptions, this guide provides a glossary of anatomical terms used as well as annotated figures of specimens. It will begin with beetles most likely to be found inside a coffee berry and then will focus on beetles likely to be found in $\mathrm{CBB}$ traps.

\section{Coffee Berry Borer, Hypothenemus hampei}

This section will describe the important morphological characters needed to identify CBB (Figure 1) from similar bark beetles. For specialist terms used in the descriptions, see figures and glossary.

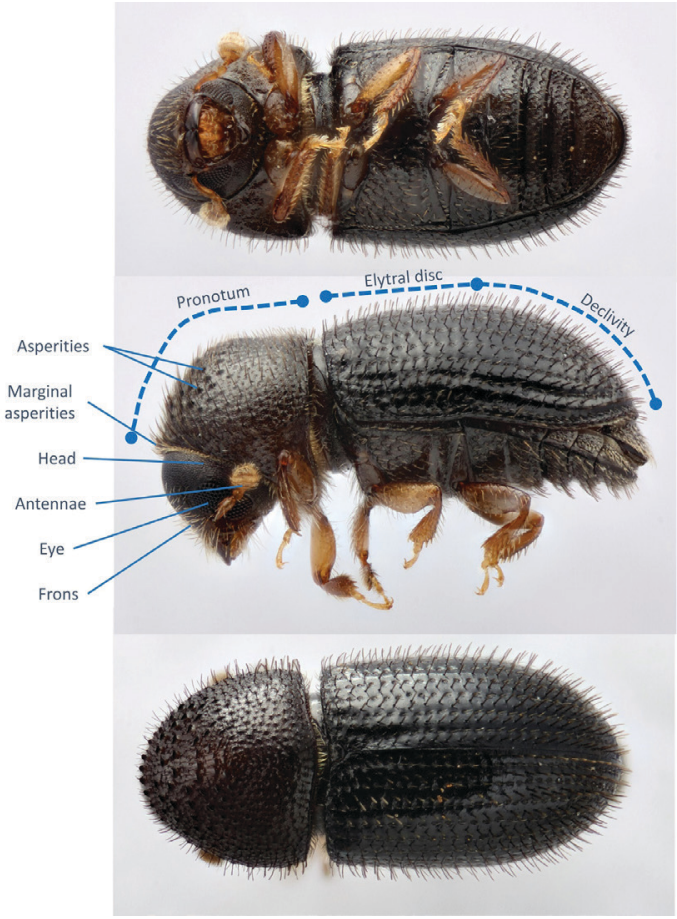

Figure 1. Coffee berry borer (CBB), Hypothenemus hampei. Specimen from East Java, Indonesia.

Credits: Andrew Johnson, UF/IFAS

1. This document is FOR377, one of a series of the School of Forest, Fisheries, and Geomatics Sciences. Original publication date February 2022. Visit the EDIS website at https://edis.ifas.ufl.edu for the currently supported version of this publication.

2. Andrew Johnson, assistant research scientist; Gabriel LeMay, graduate research assistant; and Jiri Hulcr, associate professor; School of Forest, Fisheries and Geomatics Sciences, UF/IFAS Extension, Gainesville, FL 32611.

The Institute of Food and Agricultural Sciences (IFAS) is an Equal Opportunity Institution authorized to provide research, educational information and other services

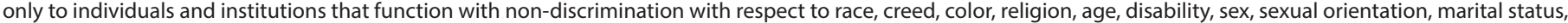

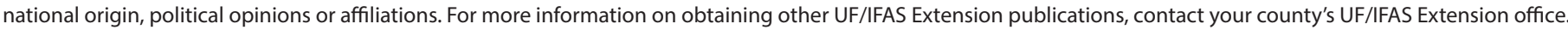
U.S. Department of Agriculture, UF/IFAS Extension Service, University of Florida, IFAS, Florida A \& M University Cooperative Extension Program, and Boards of County Commissioners Cooperating. Andra Johnson, dean for UF/IFAS Extension. 


\section{Eye and Antennae}

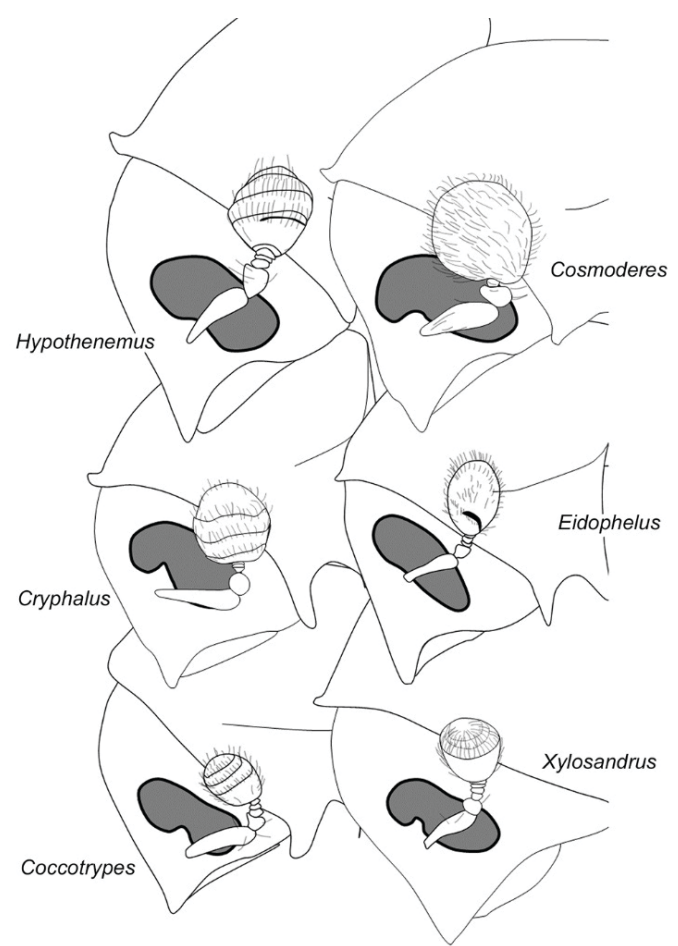

Figure 2. Eye and antennae of bark beetle genera similar to CBB. Credits: Andrew Johnson, UF/IFAS

The morphology of the eye and antennae are very important for identification of bark beetles to genus. Figure 2 illustrates the differences between genera. These features are useful to distinguish Hypothenemus from other bark beetles but not useful to tell CBB from other Hypothen-emus, since there is only limited variation within this genus.

Eyes may have different shapes and be either emarginated or entire (Figure 3). Important antennal characters to note are the shape and presence of a partial septum and sutures. Hypothenemus have three sutures marked with setae, and a septum visible as a dark line (Figure 4). This can be difficult to see with poor-quality specimens or specimens with very dark antennae. The septum is sometimes easier to see when specimens are in ethanol.

\section{Setae on the elytra}

The setae on the elytra are important for separating CBB from other Hypothenemus species, as very few have the same setae shape and arrangement as CBB. All Hypothenemus have a mixture of different setae types (Figure 5). The strial setae (those in line with the rows of punctures) are always in perfect rows and are normally small, hair-like, and curved. The interstrial setae (those in between the rows of punctures) are also usually in perfect rows, but are larger and erect. Most other Hypothenemus have interstrial bristles that are flattened and widened at the tip. CBB interstrial bristles are straight and slightly flattened but not wider at the tip. A third type of setae, which are absent in $\mathrm{CBB}$ and present in many other Hypothenemus, are usually only on the declivity and are not always in neat rows.

Cryphalus bicolor is similar to CBB but can be easily distinguished by the elytra; the strial setae are not in perfect rows. It is likely that some Eidophelus species from New Guinea would have setae similar to CBB, however all of the species found so far have interstrial bristles which are slightly curved and are much shorter on the elytral disc than on the elytral declivity, whereas CBB have them all of a similar size. They can also be distinguished by the eye and antennae, plus the separation of the mesocoxae.

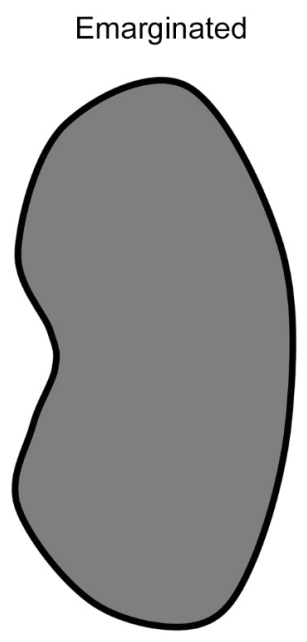

Eye is notched

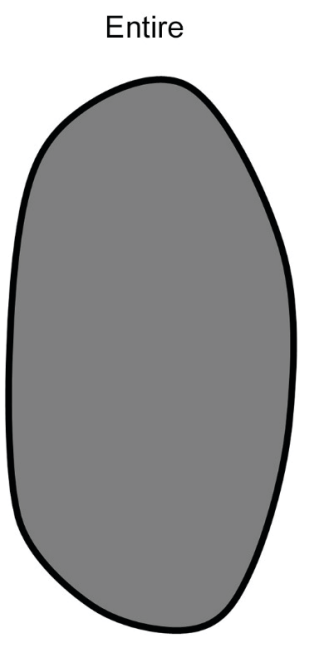

Eye is not notched, the margin is rounded
Figure 3. Differences in eye shape between some bark beetles. CBB has an emarginated eye.

Credits: Andrew Johnson, UF/IFAS

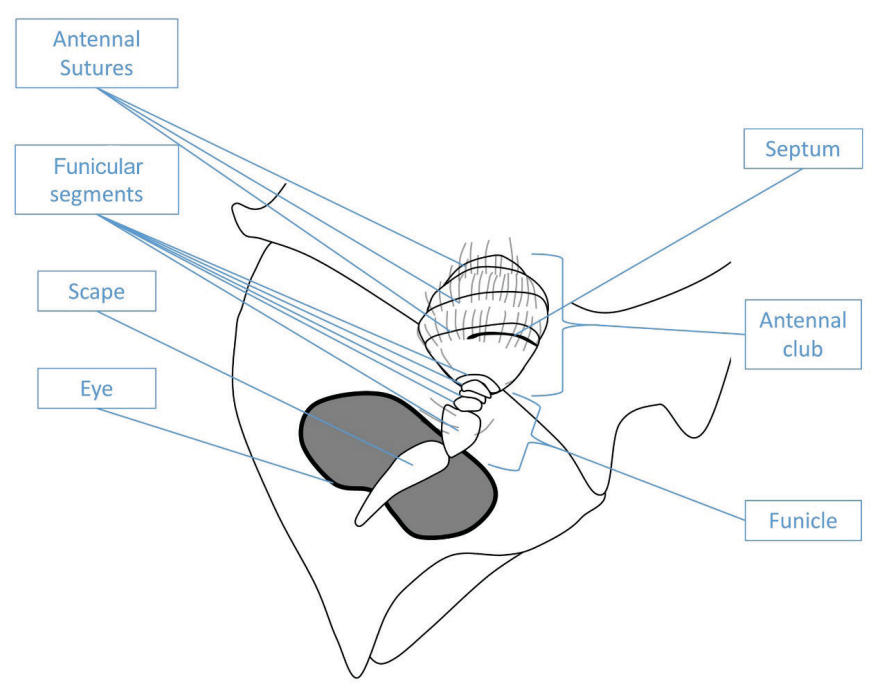

Figure 4. Coffee berry borer eye and antennae. Credits: Andrew Johnson, UF/IFAS 


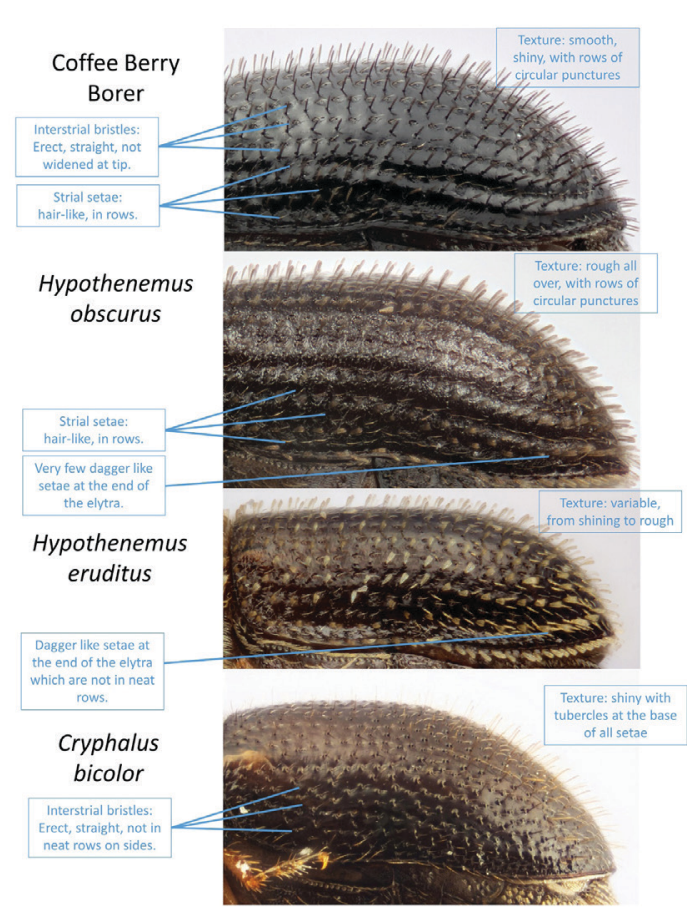

Figure 5. The elytra of CBB and similar bark beetles. The shape of the interstrial bristles and the texture of the elytra are useful characters for identification of CBB from similar beetles.

Credits: Andrew Johnson, UF/IFAS

\section{Other important characters}

The separation of the coxae is a character which can help identify some genera (Figure 6). The procoxae of CBB are contiguous, meaning they touch in the middle of the body, though they may be separated if the forelimbs are held apart. Species with separated procoxae can never be contiguous. The separated procoxae is especially obvious in some genera, such as Xylosandrus. The separation of the mesocoxae and metacoxae may also be informative. For Hypothenemus species, the mesocoxae and metacoxae are separated by a similar distance. For many Eidophelus species and some Cryphalus species, the mesocoxae are much further apart than the metacoxae.

The legs, particularly the hind tibia, are a useful character for distinguishing Hypothenemus from other genera. To see the characters on the legs requires observation under a good stereo microscope with diffused lighting, or the legs mounted on a slide. Hypothenemus have very few denticles (the spine-like structures) on the tibia. Denicles are only found at the apex (furthest from the body) in Hypothenemus. The shape is also narrow and straight. Many other genera have denticles that are present over one-third or more of the length of the tibia, or that are flattened with a semicircular margin (for example, see Xylosandrus spp.).

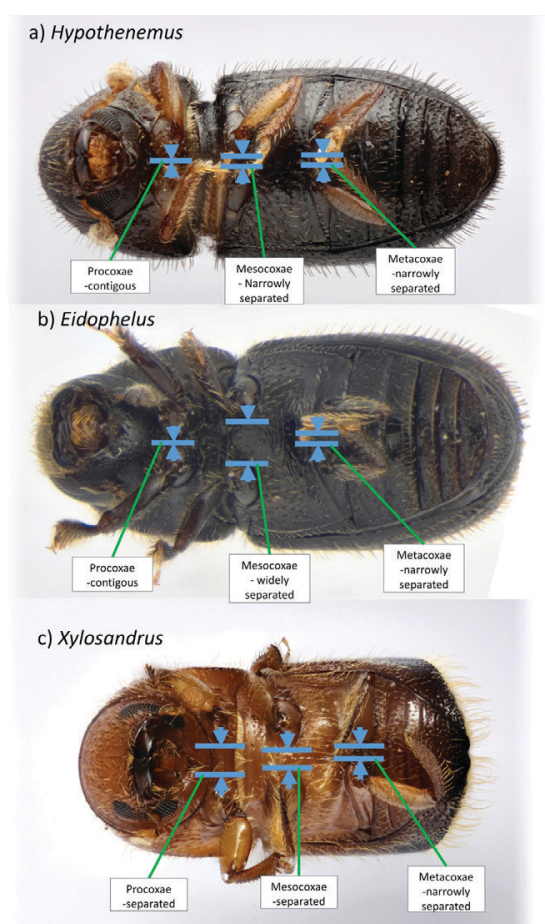

Figure 6. The separation of the coxae is useful to tell some genera apart. Not shown are Cryphalus, which is usually the same as A (rarely B), as well as Cosmoderes and Coccotrypes, which are also the same as A.

Credits: Andrew Johnson, UF/IFAS

\section{Morphology of male CBB}

Male Hypothenemus hampei (Figure 7) spend their entire life in the coffee berry. They are unlikely to be found on their own. They can be easily distinguished from the females by their smaller size (typically $1.2 \mathrm{~mm}$ ), smaller eye, and shorter body shape.

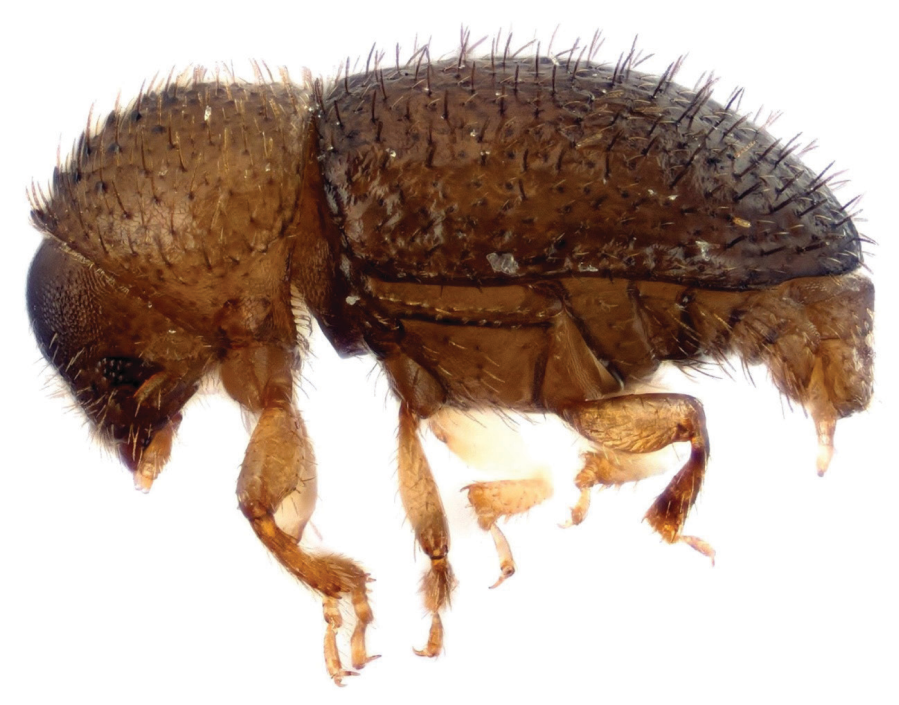

Figure 7. Male coffee berry borer.

Credits: Andrew Johnson, UF/IFAS

Male Hypothenemus are often very difficult to identify to species because they usually have different morphology from the females. For many species, the males are not 
described or known. Generally, however, they have longer setae that are sometimes not flattened and are similar to those of CBB. Males should never be used for diagnosis or identification of CBB.

\section{Distinguishing CBB from other species in the genus Hypothenemus}

The species diversity of Hypothenemus is greatest in Africa and the Americas. There are 10 named species recognized from the Austro-Pacific region, 21 known from Asia (Hulcr et al., 2015), and likely many more cryptic species that cannot be easily distinguished. Figure 8 shows a few examples of Hypothenemus species found in New Guinea. Most Hypothenemus species live in twigs and vines. They usually feed on a very wide range of host species.

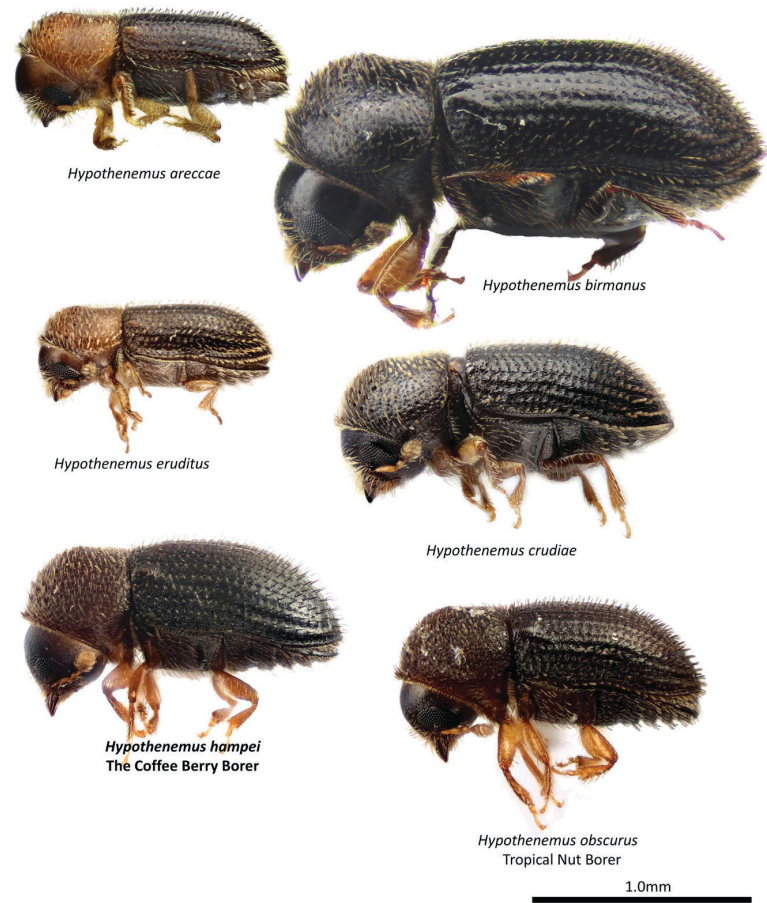

Figure 8. Examples of Hypothenemus species found in New Guinea. Credits: Andrew Johnson, UF/IFAS

Hypothenemus can be distinguished from other bark beetles by the antennal sutures and septum, the emarginated eye, the presence of asperities (raised bumps) on both the margin and slope of the pronotum, the contiguous procoxae and closely separated mesocoxae, and the hind tibia, which have almost no spines except at the end.

New galleries (excavated portion of the plant where beetles reside) usually contain just one beetle, a female. The species most commonly found in New Guinea are Hypothenemus birmanus and $H$. eruditus. The species $H$. areccae, $H$. crudiae, and $H$. eridutus have all been recorded in coffee berries (Figure 9). They tend to only live in old, black berries, making galleries similar to $\mathrm{CBB}$.

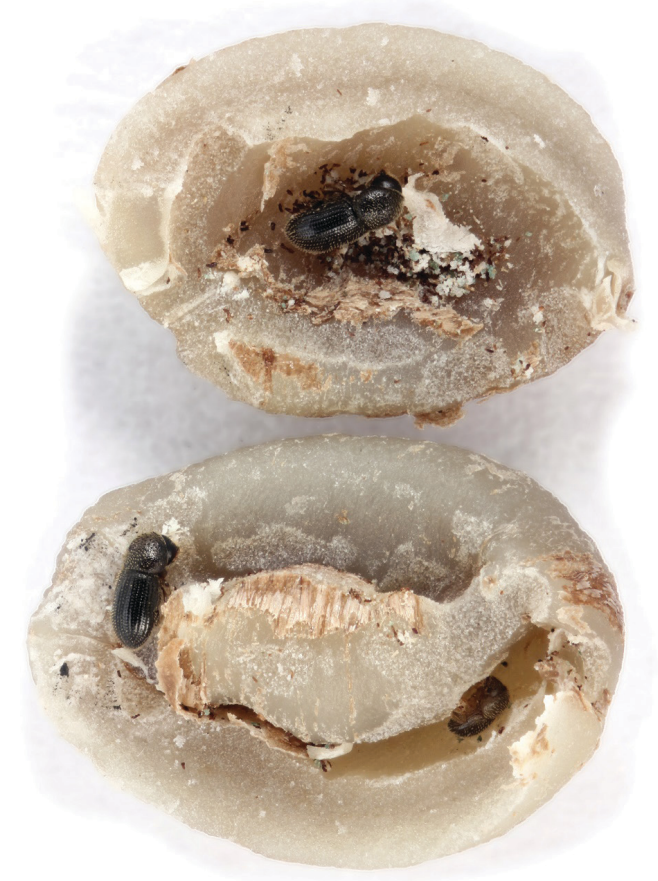

Figure 9. Old coffee berry with Hypothenemus crudiae. Credits: Andrew Johnson, UF/IFAS

\section{Tropical nut borer, Hypothenemus obscurus}

The tropical nut borer (TNB) is another Hypothenemus pest species known to occur in the Americas and Hawaii. There are also unconfirmed reports of TNB from Southeast Asia and Africa. It is not yet known from Papua New Guinea or Australia. It is of particular concern to the macadamia nut industry and has caused millions of dollars of damage in Hawaii, where the TNB has continued to spread. TNB has also been found in coffee berries.

While TNB is easy to distinguish from CBB based on the characters above, the species is much more difficult to distinguish from other Hypothenemus, because many species share similar characters. Generally, it can be identified by the size ( 1.3 to $1.8 \mathrm{~mm}$ ), the flattened setae arranged in rows, the very rough microtexture of the elytra, and the presence of very few dagger-like interstrial setae on the declivity. Genetic data is available for this species (Mitchell and Maddox, 2010) for molecular-based identification. 


\section{Distinguishing CBB from beetles in other genera}

\section{Xylosandrus}

Xylosandrus is one genus in a very diverse group of ambrosia beetles (tribe Xyleborini). They are among the most commonly collected bark beetles in traps. Xylosandrus compactus usually attacks and kills living twigs. It can be a pest to stressed trees and a severe pest to saplings. Occasionally, specimens of this species also bore into coffee berries.

Xylosandrus all have a very large head and pronotum that is almost as big as the elytra (Figure 10). They can be identified by their widely spaced procoxae (Figure 6). This is especially obvious in Xylosandrus compactus and X. morigerus, but only narrowly separate in $X$. crassiusculus. There are many other genera of beetles that have a very similar appearance but do not have separated procoxae.

New galleries usually contain only one beetle, a female. The males are much smaller and mate with their siblings, and do not usually leave their gallery. The galleries of Xylosandrus usually are in the wood or pith of twigs or branches, where the beetles farm fungi for nutrition.

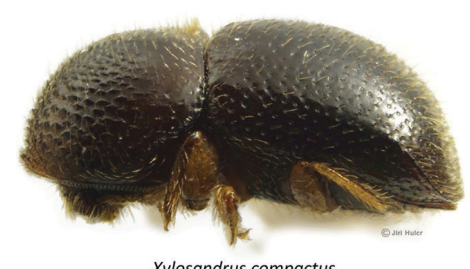

Xylosandrus compactus

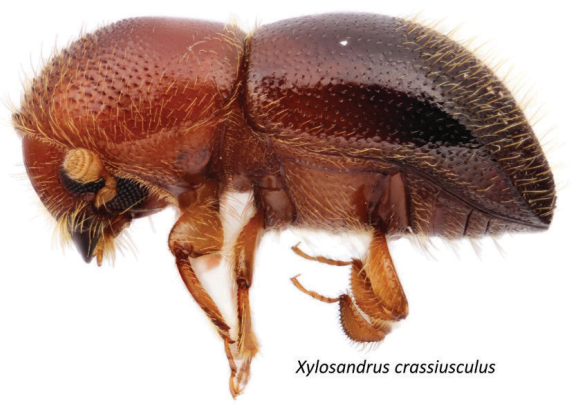

Figure 10. Examples of species of Xylosandrus present in New Guinea. Credits: Andrew Johnson, UF/IFAS and Jiri Hulcr, UF/IFAS

The following genera are less likely to be found in a coffee berry but may be found in traps for CBB.

\section{Cryphalus}

Cryphalus (Figure 11) are very common and very diverse in Southeast Asia and Oceania. They can be distinguished by the antennae, which have sutures but do not have a septum.
The majority of species also have short, very dense setae across the whole elytra. Most species also have their third tarsal segment bilobed (two large lobes) extending either side of the fourth tarsomere, whereas Hypothenemus always has a single lobe projecting under the fourth tarsomere. This is however not clear in some species, especially those that are very small.
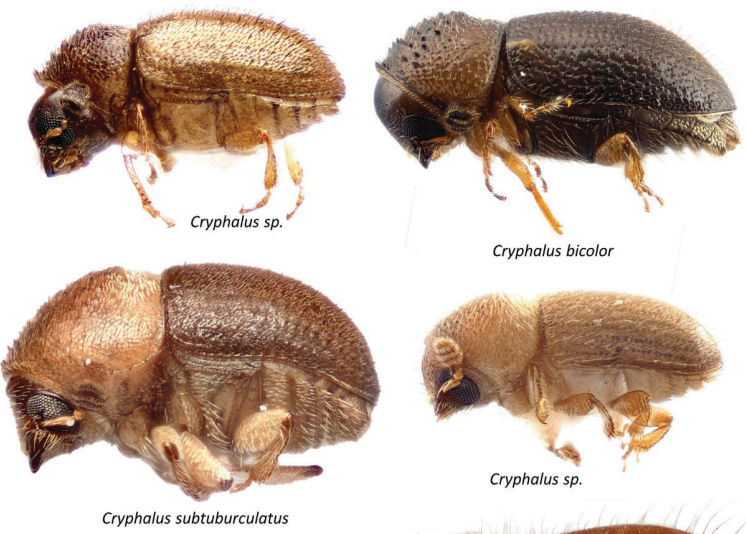

Cryphalus subtuburculatus

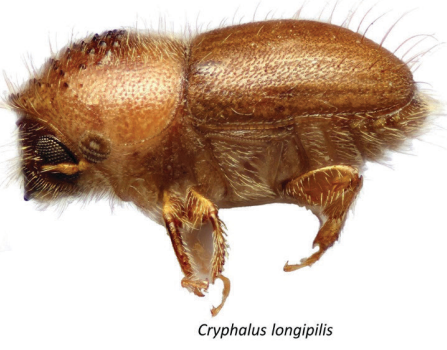

Figure 11. Examples of Cryphalus species found in New Guinea. Credits: Andrew Johnson, UF/IFAS

Cryphalus are usually found under bark or in the pith of twigs of trees, although some species are found in vines or other plant tissues. New galleries usually contain two beetles, a male and a female. Most species feed on only one type of plant, but none are known from coffee. Therefore, you can potentially find Cryphalus in a trap, but never inside coffee berries.

\section{Cosmoderes}

Cosmoderes (Figure 12) is closely related to Hypothenemus (Johnson et al, 2020). Both males and females are of a similar size, and both are able to fly. New galleries usually contain two beetles, one male and one female.

They can easily be distinguished from Hypothenemus by the antennae, which have a large antennal club that is completely without sutures, and an antennal funicle that is short with just two segments. They are commonly collected in vines and will occasionally fly into CBB traps. 


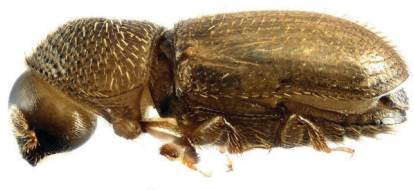

Cosmoderes sp.

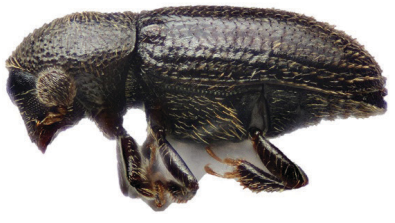

Cosmoderes sp.
Figure 12. Examples of Cosmoderes. Credits: Andrew Johnson, UF/IFAS

\section{Eidophelus}

Eidophelus (Figure 13) is a very diverse genus with lots of variation in shape and size. They can be identified and distinguished from Hypothenemus by their antennal club, which does not have sutures, and often has a septum (Figure 4). The mesocoxae are usually much more widely separated than the metaxocae (Figure 6). Some Eidophelus lack any septum on the antennae. They are easily distinguished from Cosmoderes by the antennae, which have three or more segments of the funicle, a smaller antennal club, and widely separated mesocoxae.

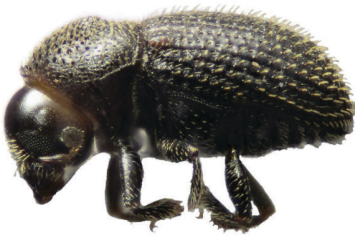

Eidophelus sp.

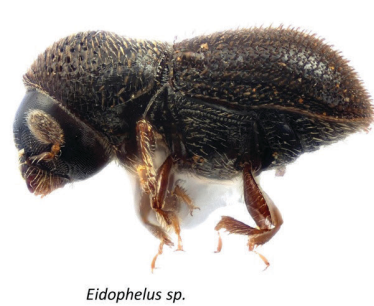

Eidophelus sp.

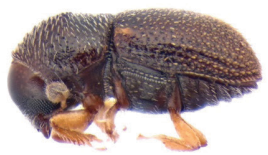

Eidophelus sp.

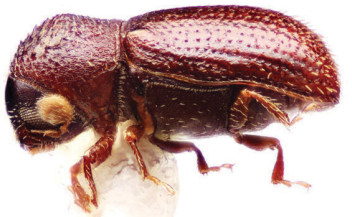

Eidophelus papuanus
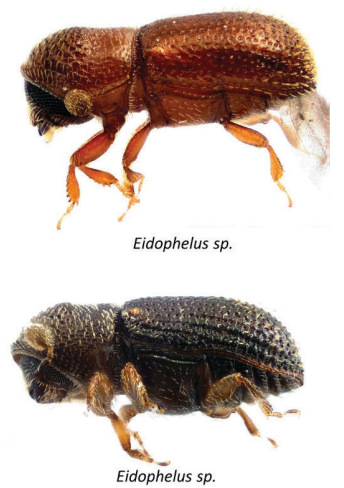

$1.0 \mathrm{~mm}$
Figure 13. Examples of Eidophelus found in New Guinea.

Credits: Andrew Johnson, UF/IFAS

Eidophelus species usually feed on one particular type of plant. Some species live under bark, while others live in the petioles of large leaves. New galleries usually contain two beetles, a male and a female.

\section{Coccotrypes}

Coccotrypes (Figure 14) is a very diverse genus found throughout the tropics. They live in a wide range of host

materials, with some species occurring in bark, some in petioles, and some in seeds. The seed-feeding species are often a similar shape to CBB. The antennae of Coccotrypes lack a septum, and the hind tibia are widened and have several spines, which are not restricted to the very end as in CBB. Many species also have a flattened pronotum.
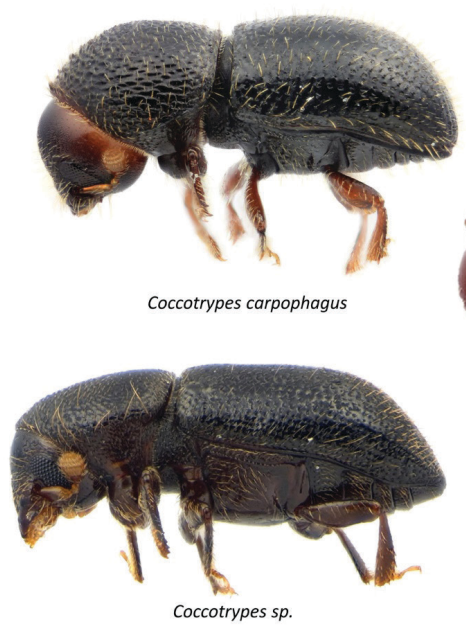

Coccotrypes carpophagus

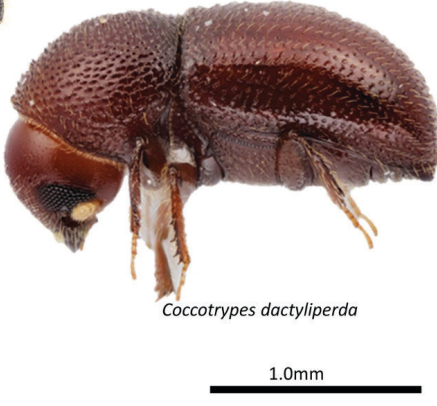

Figure 14. Examples of species in the genus Coccotrypes. Credits: Andrew Johnson, UF/IFAS

New galleries usually contain only one beetle, a female. The males are much smaller and mate with their siblings, and do not usually leave their gallery.

\section{Further reading on other bark and ambrosia beetles}

There are more than six thousand bark beetle species. Most other genera present in areas with $\mathrm{CBB}$ are easily distinguished from CBB. Figure 15 shows two examples of other Scolytine genera which may be found in Papua New Guinea.

Xyleborini is a very diverse tribe of beetles thatare routinely caught in CBB-targeted traps due to their attraction to ethanol. This guide covers many of the beetles that may be encountered in $\mathrm{CBB}$ management, and additional publications are available to identify genera and species not included here. For a comprehensive guide to the genera and species of Xyleborini, see the book by Hulcr and Cognato (2013) for Papua New Guinea, and the monograph by Smith et al.(2020) for Southeast Asia. 

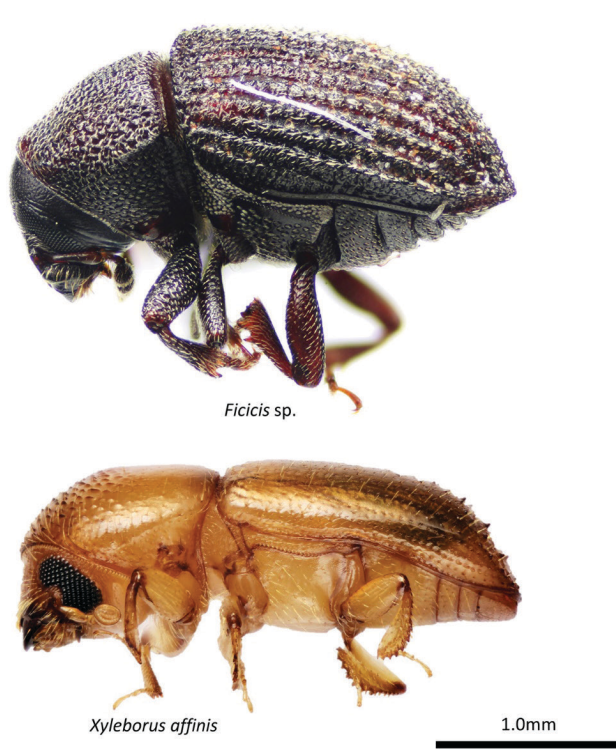

Figure 15. Examples of other Scolytine genera. Show above are Ficicis porcatus and Xyleborus affinis.

Credits: Andrew Johnson, UF/IFAS

\section{Glossary}

\begin{tabular}{|c|c|}
\hline Antennal club & $\begin{array}{l}\text { The widened, large part at the end of the } \\
\text { antennae. }\end{array}$ \\
\hline Coxa & $\begin{array}{l}\text { The segment of the leg which attaches to the } \\
\text { body. Procoxae = front legs, mesocoxae = } \\
\text { middle legs, metacoxae = rear legs. }\end{array}$ \\
\hline Declivity & $\begin{array}{l}\text { The sloping, posterior portion of the elytra (see } \\
\text { Figure 1). }\end{array}$ \\
\hline $\begin{array}{l}\text { Elytron (plural = } \\
\text { elytra) }\end{array}$ & The hard wing covering of a beetle. \\
\hline Elytral disc & The anterior portion of the elytra (see Figure 1 ). \\
\hline Emarginated & $\begin{array}{l}\text { Notched. "Emarginated" is normally used to } \\
\text { describe the shape of the eye, where the notch } \\
\text { is usually around or above the base of the } \\
\text { antennae. }\end{array}$ \\
\hline Funicle & $\begin{array}{l}\text { The section of the antennae between the scape } \\
\text { and the club, which is made up of two or more } \\
\text { segments including the pedicel. }\end{array}$ \\
\hline Interstrial bristles & $\begin{array}{l}\text { The setae found in between the punctures } \\
\text { on the elytra. These are the largest and most } \\
\text { prominent setae on the elytra of CBB. }\end{array}$ \\
\hline Pedicel & $\begin{array}{l}\text { The second segment of the antennae, which is } \\
\text { usually round and wider than the others. It is } \\
\text { also the called the first funicular segment. }\end{array}$ \\
\hline Pronotum & $\begin{array}{l}\text { The upper surface of the first segment of the } \\
\text { thorax. In bark beetles, this is large and looks } \\
\text { like a helmet over the head. }\end{array}$ \\
\hline Scape & $\begin{array}{l}\text { The first segment of the antennae, which is } \\
\text { usually elongated. }\end{array}$ \\
\hline Setae & The hairs, scales, or bristles of an insect. \\
\hline Suture & The seam, in this case on the antennal club. \\
\hline Tarsus & $\begin{array}{l}\text { The leg segment furthest from the body. } \\
\text { Divided further into multiple smaller segments } \\
\text { (tarsomeres). }\end{array}$ \\
\hline Tibia & The fourth leg segment from the body. \\
\hline
\end{tabular}

\section{Additional Reading}

Hulcr, J., and A. I. Cognato. 2013. Xyleborini of New Guinea: A Taxonomic Monograph (Coleoptera: Curculionidae: Scolytinae). Thomas Say Publications in Entomology, The Entomological Society of America, Annapolis, MD. 172 pp.

Hulcr, J., T. H. Atkinson, A. I. Cognato, B. H. Jordal, and D. D. McKenna. 2015. Chapter 2 - "Morphology, Taxonomy, and Phylogenetics of Bark Beetles" pp 41-84. In Bark beetles. Biology and ecology of native and invasive species, edited by F. E. Vega and R. W. Hofstetter. Academic Press, Cambridge, MA, USA, 620 pp. https://doi.org/10.1016/ B978-0-12-417156-5.00002-2

Johnson, A. J., J. Hulcr, M. Knížek, T. H. Atkinson, M. Y. Mandelshtam, S. M. Smith, A. I. Cognato, S. Park, Y. Li, and B. H. Jordal. 2020. "Revision of the Bark Beetle Genera within the Former Cryphalini (Curculionidae: Scolytinae)." Insect Systematics and Diversity 4 (3): 1. https://doi. org/10.1093/isd/ixaa002

Mitchell, A., and C. Maddox. 2010. "Bark Beetles (Coleoptera: Curculionidae: Scolytinae) of Importance to the Australian Macadamia Industry: An Integrative Taxonomic Approach to Species Diagnostics." Australian Journal of Entomology 49 (2): 104-113. https://doi. org/10.1111/j.1440-6055.2010.00746.x

Smith, S. M., R. A. Beaver, and A. I. Cognato. 2020. "A Monograph of the Xyleborini (Coleoptera, Curculionidae, Scolytinae) of the Indochinese Peninsula (except Malaysia) and China." ZooKeys 983:1. https://doi.org/10.3897/ zookeys.983.52630 